\title{
FIRST PLY FAILURE ANALYSIS OF LAMINATED COMPOSITE BEAM FOR DIFFERENT BOUNDARY CONDITIONS UNDER THERMO MECHANICAL LOADING
}

\author{
ARNAB CHOUDHURY* \\ Research Scholar, Department of Mechanical Engineering \\ Jadavpur University \\ Kolkata, INDIA \\ E-mail: arnabmech001@gmail.com \\ SAMAR CHANDRA MONDAL and SUSENJIT SARKAR \\ Faculty, Department of Mechanical Engineering \\ Jadavpur University \\ Kolkata, INDIA
}

\begin{abstract}
Failure analysis of a laminated composite beam subjected to uniformly distributed load and thermal load is studied for different boundary conditions and fiber orientation angles, based on first ply failure load. Three different boundary conditions are studied: simply supported, fixed-fixed and fixed-free. The strength ratio is computed and compared for different failure theories. The effect of fiber orientation angle and aspect ratio on the strength ratio based on first ply failure load is presented in the paper. The strength ratio and transverse deflection are determined for Graphite/Epoxy and Glass/Epoxy composite and their hybrid combinations to find out the optimum hybrid composite beam with minimum weight, deflection and cost. The problem is solved in MATLAB platform. The mode of failure of the composite beam is determined by using maximum stress theory.
\end{abstract}

Key words: first ply failure load, fiber orientation angle, aspect ratio, hybrid composite beam, strength ratio.

\section{Introduction}

A composite material is a system of materials consisting of two or more phases on a macroscopic scale, whose properties are more superior to that of its constituent materials. The reinforcement phase is discontinuous, stiffer and stronger as compared to the matrix phase. Fibre reinforced laminated composite structures are extensively used in different applications due to better stiffness-to-weight and strength-toweight ratios as compared to other conventional materials. Failure analysis of a laminate is more complex than that of a single lamina and requires accurate prediction of strength of each lamina by assessing the stresses to its principle axis in each lamina and by applying suitable failure criteria. Strength of a laminate depends on the lamina orientation angle, strength, stiffness, coefficient of thermal and moisture expansion, stacking sequence and finally the fabrication process which affects the residual stresses, which in turn affect the strength of laminate. The load at which the first lamina fails within a laminate is called first ply failure load.

Many research works are available on the analysis of a laminated composite beam for different boundary conditions, materials, sections and fibre orientations. Borkar et al. [1] performed bending analysis of a simply supported composite beam by using refined beam theories which account for the parabolic variation of shear strain through the depth of the beam, thus eliminating the use of shear correction factor. Trung-Kien Nguyen et al. [2] present a new analytical solution based on a higher-order beam theory for static, buckling and vibration of laminated composite beams for different boundary conditions. Sayyad et al. [3] present a review article on bending, buckling and free vibration of laminated composite and sandwich

\footnotetext{
* To whom correspondence should be addressed
} 
beams. Meng et al. [4] developed three-dimensional (3D) Finite Element Analysis (FEA) to investigate the effect of fibre lay-up on the initiation of failure of laminated composites in bending. They applied Tsai-Hill failure criterion to identify the critical areas of failure in composite laminates. Research on thermo mechanical analysis of composite beam for different fiber orientation angle is very rare. Also, comparative analysis of different failure theories is rare.

The objective of this work is to study the effect of fiber orientation angle on first ply failure analysis of a symmetric angle ply and cross ply laminated composite beam for different boundary conditions under thermo mechanical loading. The strength ratio is calculated based on first ply failure load, using Tsai-Wu failure criteria for the beam subjected to uniformly distributed load (mechanical load) and combined thermal and mechanical load and they are compared with each other. Three different boundary conditions are considered in this paper. First, the beam is simply supported at both the ends, second, the beam is fixed at both the ends and third, the beam is fixed at one end and free at the other end. The strength ratio is determined and compared for these three boundary conditions. The mode of failure is determined using the maximum stress theory for the above boundary conditions for two different loadings: mechanical and thermo mechanical load. This mode of failure may be used for determining the ultimate failure load as well as the type of failure of the beam. The strength ratio is determined and compared for two different failure theories: interactive and non interactive, which may be important to find out the best theory which accurately depicts the failure of the beam. A hybrid composite beam is developed from Graphite/Epoxy and Glass/Epoxy composite plies with minimum deflection, cost, weight and maximum strength. The equations are solved by using MATLAB software.

\section{Theoretical formulation}

A laminated composite beam of rectangular section $(b x h)$ and height $a$ as shown in Fig.1 is considered. The beam is composed of four plies of composite material of different fibre orientations with respect to the $x$ axis. $\theta$ is the fiber orientation angle between the material coordinate system $\left(x_{1}\right)$ and reference coordinate system $(x)$
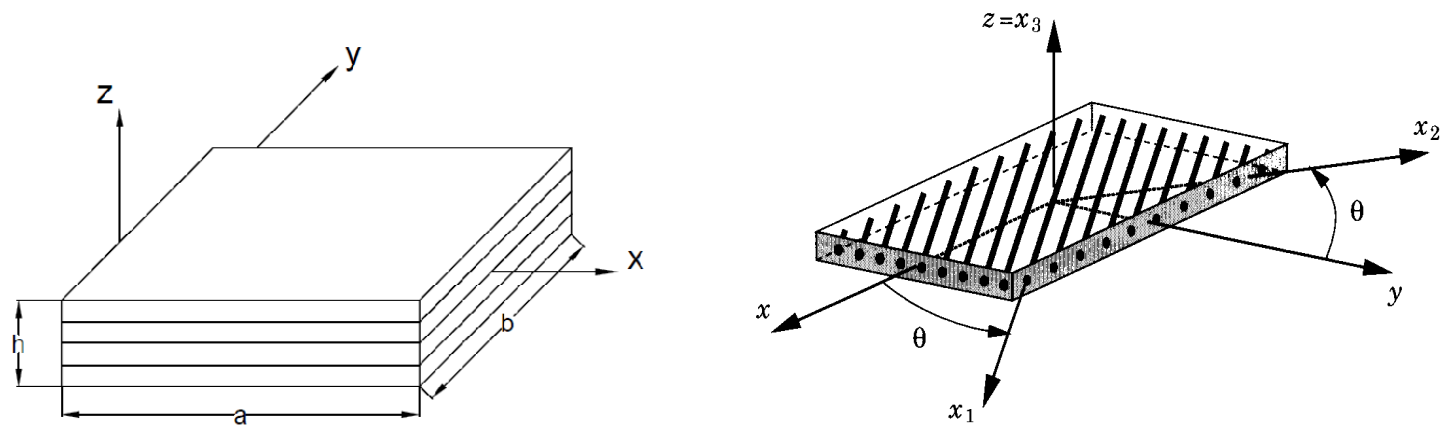

Fig.1. Geometry of a laminate (left) and a single ply or lamina (Right).

Transverse deflection and stresses in the material coordinate system are found out using the classical laminated plate theory (CLT) with the assumptions of Kirchhoff hypothesis. The displacement $(u, v, w)$ can be written as [5]

$$
\begin{aligned}
& u(x, y, z, t)=u_{0}(x, y, t)-z \frac{\partial w_{0}}{\partial x}, \\
& v(x, y, z, t)=v_{0}(x, y, t)-z \frac{\partial w_{0}}{\partial y}, \\
& w(x, y, z, t)=w_{0}(x, y, t)
\end{aligned}
$$


where, $\left(u_{0}, v_{0}, w_{0}\right)$ are the displacements along the material coordinate system.

The general solution of the bending equation [5] is

$$
E_{x x}^{b} I_{y y} w_{0}(x)=\int_{0}^{x}\left\{\int_{0}^{\xi}\left[\int_{0}^{\eta}\left(\int_{0}^{\varsigma} q(\mu) d \mu\right) d \varsigma\right] d \eta\right\} d \xi+c_{1} \frac{x^{3}}{6}+c_{2} \frac{x^{2}}{2}+c_{3} x+c_{4}
$$

The constant of integration can be determined from the boundary conditions of the problem.

Boundary conditions for different type of supports are as follows

Free: $\quad Q=\frac{d M}{d x}=0, \quad M=0$.

Hinged: $\quad w_{0}=0, \quad M=0$.

Clamped: $\quad w_{0}=0, \quad \frac{\partial w_{0}}{\partial x}=0$

The in-plane stresses in the $k^{\text {th }}$ layer can be determined as

$$
\left\{\begin{array}{l}
\sigma_{x x} \\
\sigma_{y y} \\
\sigma_{x y}
\end{array}\right\}^{(k)}=z\left[\begin{array}{lll}
\bar{Q}_{11} & \bar{Q}_{12} & \bar{Q}_{16} \\
\bar{Q}_{12} & \bar{Q}_{22} & \bar{Q}_{26} \\
\bar{Q}_{16} & \bar{Q}_{26} & \bar{Q}_{66}
\end{array}\right]^{(k)}\left\{\begin{array}{c}
\frac{\partial^{2} w_{0}}{\partial x^{2}} \\
\frac{\partial^{2} w_{0}}{\partial y^{2}} \\
2 \frac{\partial^{2} w_{0}}{\partial x \partial y}
\end{array}\right\} .
$$

The constants in the expressions are defined as

$$
b_{2}=\frac{q_{0} b a^{4}}{E_{x x}^{b} I_{y y}}, \quad b_{4}=-q_{0} b a^{2} .
$$

The non dimensional transverse deflection is given as $\widehat{w}=w_{\max }\left(E_{2} h^{3} / q_{0} a^{4}\right) * 10^{2}$.

\section{First ply failure analysis}

Failure analysis of a laminate is more complex than that of a single lamina and requires accurate prediction of strength of each lamina by assessing the stresses to its principle axis in each lamina and by applying suitable failure criteria. The strength of a laminate depends on the lamina orientation angle, strength, stiffness, coefficient of thermal and moisture expansion, stacking sequence and finally the fabrication process which affects the residual stresses, which in turn affect the strength of the laminate. When a single lamina fails, it does not mean that the whole laminate fails but it is the beginning of the failure process. Load at which the first lamina fails is called first ply failure load (FPF). The FPF approach is conservative and it is used with low factor of safety $[5,6]$. 


$$
\mathrm{SR}=\frac{\text { Maximum load applied }}{\text { Load applied }}=\frac{\text { ultimate } \text { strength }}{\text { applied } \text { stress }} .
$$

If $\mathrm{SR}>1$, then the lamina is safe and the applied stress can be increased by a factor of SR. If $\mathrm{SR}<1$, the lamina is unsafe and the applied stress needs to be reduced by a factor of SR. A value of SR $=1$ implies the failure load.

The strength ratio based on first ply failure load is determined by using different failure theories.

\section{Failure theories}

Single failure criteria are not sufficient to predict the failure of all types of laminates. Failure theories are classified into three groups:

1. Non- interactive theories (maximum stress, maximum strain theory).

2. Interactive theories (Tsai-Hill, Tsai- Wu failure theory).

3. Failure mode based theories (Hashin- Rotem, Puck theory).

Non-interactive theories such as maximum stress, maximum strain theory are simple to apply and can be used to determine the mode of failure but interactive theories like Tsai-Hill, Tsai- Wu failure theory cannot tell the mode of failure but explain the interaction of stress in failure. Failure mode based theories like Hashin- Rotem, Puck theory are used to determine the mode of failure effectively. In the present study, interactive and non-interactive theories are used to determine the strength ratio of a laminated composite beam. Also, a comparative study of these theories is conducted for the mechanical and thermo mechanical loading. The maximum stress theory is used to determine the mode of failure.

\subsection{Maximum stress failure theory}

According to the maximum stress theory a lamina is considered to be failed if [7]

$$
\begin{aligned}
& -\left(\sigma_{1}^{c}\right)_{u l t}<\sigma_{1}<\left(\sigma_{1}^{T}\right)_{u l t}, \\
& -\left(\sigma_{2}^{c}\right) \text { ult }<\sigma_{2}<\left(\sigma_{2}^{T}\right) \text { ult, } \\
& -\left(\tau_{12}\right) \text { ult }<\tau_{12}<\left(\tau_{12}\right) \text { ult is violated. }
\end{aligned}
$$

\subsection{Tsai-Wu failure theory}

Tsai- Wu failure criteria are quadratic failure criteria which take into account the interaction of stress components but they cannot be used to determine the mode of failure. A lamina is considered to be failed if

$$
H_{1} \sigma_{1}+H_{2} \sigma_{2}+H_{6} \tau_{12}+H_{11} \sigma_{1}^{2}+H_{22} \sigma_{2}^{2}+H_{11} \sigma_{1}^{2}+H_{66} \tau_{12}^{2}+2 H_{12} \sigma_{1} \sigma_{2}<1,
$$

is violated. This failure theory is more general than the Tsai-Hill failure theory because it distinguishes between the compressive and tensile strengths of a lamina. The components $H_{1}, H_{2}, H_{6}, H_{11}, H_{22}$, and $H_{66}$ of the failure theory are found using the five strength parameters of a unidirectional lamina.

\subsection{Tsai-Hill failure theory}

Tsai-Hill failure theory is based on the distortion energy failure theory of Von-Misses. Hill adopted the Von- Mises' distortional energy yield criterion to anisotropic materials. Then, Tsai adapted it to a unidirectional lamina. Based on the distortion energy theory, he proposed that a lamina has failed if 


$$
\begin{aligned}
& \left(G_{2}+G_{3}\right) \sigma_{1}^{2}+\left(G_{1}+G_{3}\right) \sigma_{2}^{2}+\left(G_{1}+G_{2}\right) \sigma_{3}^{2}-2 G_{3} \sigma_{1} \sigma_{2}-2 G_{2} \sigma_{1} \sigma_{3}+ \\
& -2 G_{1} \sigma_{2} \sigma_{3}+2 G_{4} \tau_{23}^{2}+2 G_{5} \tau_{13}^{2}+2 G_{6} \tau_{12}^{2}<1,
\end{aligned}
$$

is violated. The components $G_{1}, G_{2}, G_{3}, G_{4}, G_{5}$, and $G_{6}$ of the strength criterion depend on the failure strengths.

\section{Mode of failure}

The mode of failure is determined by using the maximum stress failure theory which states that [5]

$$
\begin{aligned}
& \sigma_{1}>0, \text { fiber failurein tension }(1 T), \\
& \sigma_{1}<0 \text {, fiber failure incompression }(1 C), \\
& \sigma_{2}>0 \text {, matrix failure in tension }(2 T), \\
& \sigma_{2}<0 \text {, matrix failurein compression }(2 C), \\
& S=\text { shear failure }\left(\gamma_{12}>0, \gamma_{12}<0\right)(S) .
\end{aligned}
$$

\section{Constitutive model}

A laminated composite structure (beam) is a collection of lamina arranged in a specified manner. Consider a laminated composite beam made up of number of lamina bonded together perfectly and reinforced by fibers in a definite orientation and which is symmetric to its mid plane subjected to mechanical load (uniformly distributed, UDL) and thermal load $(\Delta T)$. The classical lamination theory (CLT) is applicable for thin laminates, i.e. thickness is small relative to the lateral dimensions and deformation is small. Stress and strain with reference to the principal axis $(1,2)$ in each layer can be determined by the classical lamination theory or first order deformation theory because both the theories yield the same stress.

\subsection{Mechanical stress}

The constitutive equations for a general linear elastic solid relate the stress and strain tensors through the expression [5]:

Moreover, the stress- strains relations in 1-2 planes are

where

$$
\left[\begin{array}{c}
\sigma_{1} \\
\sigma_{2} \\
\sigma_{3}
\end{array}\right]=\left[\begin{array}{ccc}
Q_{11} & Q_{12} & Q_{11} \\
Q_{12} & Q_{22} & 0 \\
0 & 0 & Q_{66}
\end{array}\right]\left[\begin{array}{c}
\varepsilon_{1} \\
\varepsilon_{2} \\
\gamma_{12}
\end{array}\right]
$$

$$
Q_{11}=\frac{E_{1}}{1-v_{12} v_{21}}, \quad Q_{22}=\frac{E_{2}}{1-v_{12} v_{21}}, \quad Q_{12}=\frac{v_{12} E_{2}}{1-v_{12} v_{21}}, \quad Q_{66}=G_{12}, \quad \frac{v_{12}}{E_{1}}=\frac{v_{21}}{E_{2}} .
$$

The stress strain relation in the $x-y$ coordinate system is 


$$
\left[\begin{array}{c}
\sigma_{x} \\
\sigma_{y} \\
\tau_{x y}
\end{array}\right]=\left[\begin{array}{lll}
\bar{Q}_{11} & \bar{Q}_{12} & \bar{Q}_{16} \\
\bar{Q}_{12} & \bar{Q}_{22} & \bar{Q}_{26} \\
\bar{Q}_{16} & \bar{Q}_{26} & \bar{Q}_{66}
\end{array}\right]\left[\begin{array}{c}
\varepsilon_{x} \\
\varepsilon_{y} \\
\gamma_{x y}
\end{array}\right]
$$

Combining the above two matrices as

$$
\left\{\begin{array}{l}
N \\
M
\end{array}\right\}=\left[\begin{array}{ll}
A & B \\
B & D
\end{array}\right]\left[\begin{array}{l}
\varepsilon^{0} \\
k
\end{array}\right],
$$

$A_{i j}($ extensional stiffness matrix $)=\sum_{k=1}^{n}\left[\overline{Q_{i j}}\right]_{k}\left(h_{k}-h_{k-1}\right), \quad i=1,2,6, \quad j=1,2,6$,

$B_{i j}($ extension - bending coupling matrix $)=\frac{1}{2} \sum_{k=1}^{n}\left[\left[\overline{Q_{i j}}\right]\right]_{k}\left(h_{k}^{2}-h_{k-1}^{2}\right), \quad i=1,2,6, \quad j=1,2,6$,

$D_{i j}$ (bending stiffness matrix $)=\frac{1}{3} \sum_{k=1}^{n}\left[\left[\overline{Q_{i j}}\right]\right]_{k}\left(h_{k}^{3}-h_{k-1}^{3}\right), \quad i=1,2,6, \quad j=1,2,6$

where $N, M=$ normal force and bending moment per unit length,

$\varepsilon^{0}=$ mid plane strains of laminate in the $x-y$ coordinate and $k=$ laminate curvature.

The constitutive equations for symmetric laminates in the absence of in-plane forces are given by [2]

$$
\begin{aligned}
& \left\{\begin{array}{l}
M_{x x} \\
M_{y y} \\
M_{x y}
\end{array}\right\}=-\left[\begin{array}{lll}
D_{11} & D_{12} & D_{16} \\
D_{12} & D_{22} & D_{26} \\
D_{16} & D_{26} & D_{66}
\end{array}\right]\left\{\begin{array}{c}
\frac{\partial^{2} w_{0}}{\partial x^{2}} \\
\frac{\partial^{2} w_{0}}{\partial y^{2}} \\
2 \frac{\partial^{2} w_{0}}{\partial x \partial y}
\end{array}\right\}, \\
& E_{x x}^{b}=\frac{12}{h^{3} D_{11}^{*}}, \quad I_{y y}=\frac{b h^{3}}{12} \quad \text { where } \quad D_{11}^{*}=\operatorname{inv}\left(D_{11}\right) .
\end{aligned}
$$

where $E_{x x}^{b}$, effective bending modulus of beam and $I_{y y}$, second moment of area with respect to the $x-y$ plane is given as

Stress and strain with reference to the principal axis $(1,2)$ in each layer

$$
[\sigma]_{1,2}^{k}=T^{*}[\bar{Q}]_{k}\left\{\left[\varepsilon^{0}\right]+h[k]\right\}, \quad[\varepsilon]_{1,2}^{k}=\operatorname{inv}([Q]) *[\sigma]_{1,2}^{k}
$$

\subsection{Thermo mechanical stress}

Composite materials are processed at high temperatures and then cooled down to room temperatures. Some composite structures operate at high temperature, different from the operating temperature. Due to mismatch of the coefficients of thermal expansion of the fiber and matrix, residual stresses develop in a 
lamina. Due to this a thermal strain is developed in the lamina. Laminate, oriented at different angles within the laminate have different thermal strains. Each lamina in a laminate gets stressed by the deformation differences of adjacent lamina. This difference produces mechanical strain and stress.

The mechanical strains developed by thermal loads are

$$
\left[\varepsilon^{M}\right]=[\varepsilon]-\left[\varepsilon^{T}\right] \quad \text { where } \quad[\varepsilon]=\left[\varepsilon^{0}\right]+z[k] .
$$

The thermal stresses are given by

$$
\left[\sigma^{T}\right]=[\bar{Q}]\left[\varepsilon^{M}\right] \text {. }
$$

Mid plane strain and curvature are calculated by

$$
\left[\begin{array}{l}
N^{T} \\
M^{T}
\end{array}\right]=\left[\begin{array}{ll}
A & B \\
B & D
\end{array}\right]\left[\begin{array}{l}
\varepsilon^{0} \\
k
\end{array}\right]
$$

where $\quad\left[N^{T}\right]=\Delta T \sum_{k=1}^{n}\left[\overline{Q_{i j}}\right]_{k}[\alpha]_{k}\left(h_{k}-h_{k-1}\right), \quad\left[M^{T}\right]=\frac{1}{2} \Delta T \sum_{k=1}^{n}\left[\overline{Q_{i j}}\right]_{k}[\alpha]_{k}\left(h_{k}^{2}-h_{k-1}^{2}\right)$.

Thus, if both mechanical and thermal loads are applied, then superpose the mechanical loads to the fictitious thermal loads to find the ply-by-ply stresses and strains in the laminate or separately apply the mechanical and thermal loads and then add the resulting stresses and strains from the solution of the two problems.

\section{Algorithm based on first ply failure load}

Laminate failure is not catastrophic. If one ply fails the other ply in the laminate is still capable of taking more loads until all the plies fail. An algorithm is developed to determine the strength ratio and first ply failure load of a laminated composite beam for different boundary conditions subjected to mechanical and thermal load.

I. Enter the basic lamina properties $\left(E_{1}, E_{2}, G_{12}, \vartheta_{12}\right)$.

II. Compute the ply stiffness $[Q]_{12}$ referred to their principle material axis [Eq. 10]

III. Enter the orientation $\theta_{k}$, number of layers $n$, through the thickness coordinate $z$.

IV. Find out the transformed layer stiffness $[Q]_{x y}{ }^{k}$ referred to the laminate coordinate system $(x, y)$ [Eq.11].

V. Calculate the laminate stiffness matrices $[A],[B],[D]$ and their compliance matrix [Eq.13]

VI. Enter the mechanical loading. Apply the actual temperature change $\Delta T$.

VII. Calculate mid plane strain $\left[\varepsilon^{0}\right]_{x y}$ and curvature $[k]_{x y}$ using laminate analysis [Eq. 12].

VIII. Then bending equations are derived and their solutions are obtained by direct integration.

IX. Using the boundary conditions, the constants of integration are determined and transverse deflection is calculated using $[\mathrm{D}]$ matrix.

X. Calculate the layer strain $[\varepsilon]_{1,2}^{k}$ and stress $[\sigma]_{l, 2}^{k}$ with reference to the principal axis $(1,2)$ in each layer under a given load.

XI. Enter the five lamina strength and using a suitable failure theory as discussed in the paper, find out the strength ratio/ safety factor of each of the lamina. Then the minimum strength ratio is the desired strength ratio of the laminate.

XII. Multiplying the minimum strength ratio to the applied load gives the load level of the failure of the first ply. This load is called the First Ply Failure load (FPF). 


\section{Problem description}

Consider a laminated composite beam of length $1 \mathrm{~m}$ and width $0.2 \mathrm{~m}$, composed of four plies, symmetrically arranged about the mid plane. Angle ply and cross ply arrangement is considered for the study. The thickness of each lamina is $.005 \mathrm{~m}$. The strength ratio is calculated for the beam using the algorithm developed based on first ply failure load for two different loading conditions: mechanical load (UDL of $1000 \mathrm{~N} / \mathrm{m}$ ) and thermo mechanical (UDL and $\Delta T=-75^{\circ} \mathrm{C}$ ) and for three different boundary conditions (Tab.1). First ply failure load is chosen for analysis because it is the starting of lamina failure within a laminate and the process continues until all the lamina fail. So after the first ply failure, options are available to stop or retard the failure process by modifying the parameters contributing to failure, but after the last ply or ultimate failure, all the plies fail and there is no chance to rectify it. So first ply failure load is a very important parameter for failure analysis of composite structures.

Table 1. Maximum transverse deflections of laminated composite beam for different boundary conditions and subjected to uniformly distributed load according to CLPT [6].

\begin{tabular}{|c|c|c|c|c|c|}
\hline Boundary & Loading & Maximum Bending & \multicolumn{3}{|c|}{ Maximum transverse deflections $\left(w_{\max }\right)$} \\
\hline & & & CLPT & Location $(x)$ & (19mmomm \\
\hline $\begin{array}{l}\text { Simply } \\
\text { supported }\end{array}$ & $\begin{array}{l}\text { Uniformly distributed } \\
\text { load }\left(q_{0} b\right)\end{array}$ & $-\frac{1}{8} b_{4}$ at $x=\frac{a}{2}$ & $\frac{5}{384} b_{2}$ & $\frac{a}{2}$ & $\mathrm{mmmmm}$ \\
\hline Fixed- Fixed & $\begin{array}{l}\text { Uniformly distributed } \\
\text { load }\left(q_{0} b\right)\end{array}$ & $\frac{1}{12} b_{4}$ at $x=0$ & $\frac{1}{384} b_{2}$ & $\frac{a}{2}$ & Smanmm \\
\hline Fixed- Free & $\begin{array}{l}\text { Uniformly distributed } \\
\text { load }\left(q_{0} b\right)\end{array}$ & $\frac{1}{2} b_{4}$ at $x=0$ & $\frac{1}{8} b_{2}$ & $a$ & \\
\hline
\end{tabular}

\section{Results and discussion}

\subsection{Comparative study of different failure theories for a beam fixed at both ends under UDL}

The strength ratio is computed and compared for different failure theories based on first ply failure load for composite beam fixed at both the ends and subjected to uniformly distributed load. The beam is composed of four plies of Graphite/Epoxy composite material. Two failure theories, interactive and non interactive, are compared in this paper. The maximum stress falls in the category of non-interactive failure theory whereas Tsai-Wu and Tsai-Hill falls under the category of interactive failure theory which shows the interaction between the different stress components. But it cannot determine the mode of failure. The mode of failure is determined by the maximum stress or strain failure theory. Maximum deflection is obtained at the centre of the fixed beam and strength ratio is minimum at both the ends of the beam. From Fig. 1 and Fig.2, it is found that the strength ratio of non interactive failure criteria (maximum stress, maximum strain) is greater than that of interactive failure criteria (Tsai-Wu and Tsai-Hill) for both angle ply symmetric and cross ply symmetric arrangement of the laminated composite beam, whereas the strength ratio is same for $0^{\circ}$ and $90^{\circ}$ orientation angle for all the failure criteria. Thus it can be concluded that the strength ratio does not depend upon failure criteria for $0^{\circ}$ and $90^{\circ}$ orientation angle only. Also, it is found out that the strength ratio obtained from Tsai-Hill failure criteria is greater than that of Tsai-Wu failure criteria. So the minimum value of strength ratio is obtained at Tsai-Wu failure criteria as compared to other failure criteria. So in this paper 
Tsai-Wu failure criteria are used to find the first ply failure load for all the cases but they do not make it possible to state the mode of failure which is computed by using the maximum stress failure theory (Tab.2).

Table 2. Comparison of strength ratio from different failure criteria for different fiber orientation angle.

\begin{tabular}{|c|c|c|c|c|c|}
\hline Fiber orientation angle & \multicolumn{3}{|c|}{ Strength ratio at $x=0, a$} & \multicolumn{2}{c|}{ Max deflection at $x=a / 2$} \\
\hline Angle Ply Sym. & Maximum stress & Tsai Wu & Tsai-Hill & $w(m)$ & wbar \\
\hline 0 & 240 & 240 & 240 & $1.08 E-04$ & 0.1778 \\
\hline 15 & 74.4047 & 71.7765 & 71.9947 & $1.83 E-04$ & 0.301 \\
\hline 30 & 37.6785 & 36.3866 & 37.3498 & $3.90 E-04$ & 0.6425 \\
\hline 45 & 21.76 & 16.8792 & 18.8729 & $8.60 E-04$ & 1.417 \\
\hline 60 & 11.2204 & 9.2311 & 9.8363 & 0.0014 & 2.3663 \\
\hline 75 & 7.1203 & 6.8941 & 6.9839 & 0.0018 & 2.9577 \\
\hline 90 & 6.4 & 6.4 & 6.4 & 0.0019 & 3.125 \\
\hline Cross ply Sym. & 203.2773 & 190.0751 & 197.1989 & $1.22 E-04$ & 0.201 \\
\hline $0 / 90 / 90 / 0$ & \multicolumn{5}{|l|}{} \\
\hline
\end{tabular}

\subsection{Effect of the fiber orientation angle on the strength ratio for different boundary conditions of a composite beam subjected to mechanical load (Uniformly distributed load)}

The effect of the fiber orientation angle on a symmetric angle ply and cross ply composite beam is studied for different boundary conditions, subjected to uniformly distributed load. The strength ratio is determined by using Tsai-Wu failure criteria, based on first ply failure load. The beam is composed of four plies of Graphite/Epoxy composite material. It is observed from Tab.3 (Fig.3) that strength ratio is maximum at $0^{\circ}$ and it gradually decreases and becomes minimum at $90^{\circ}$ fiber orientation angle. It is also found that the strength ratio is minimum at maximum transverse deflection and vice versa. At $90^{\circ}$ orientation angle, transverse deflection is maximum but the strength ratio is minimum and at $0^{\circ}$ orientation angle, transverse deflection is minimum and the strength ratio is maximum. The strength ratio of a both end fixed beam is greater than the other boundary conditions whereas the strength ratio of a simply supported beam is greater than fixed - free (cantilever) beam.

Table 3. Strength ratio and transverse deflection of a composite beam for different boundary conditions under UDL. (Graphite/Epoxy composite material).

\begin{tabular}{|c|c|c|c|c|c|c|}
\hline & \multicolumn{2}{|c|}{ Simply Supported } & \multicolumn{2}{c|}{ Fixed-Fixed } & \multicolumn{2}{c|}{ Fixed-Free } \\
\hline Fiber Orientation angle & Strength Ratio & wbar & Strength Ratio & wbar & Strength Ratio & wbar \\
\hline$[0 /-0 /-0 / 0]$ & 160 & 0.88 & 240 & 0.1778 & 40 & 8.5359 \\
\hline$[15 /-15 /-15 / 15]$ & 47.85 & 1.5 & 71.7765 & 0.301 & 11.96 & 14.45 \\
\hline$[30 /-30 /-30 / 30]$ & 24.2577 & 3.21 & 36.3866 & 0.6425 & 6.06 & 30.84 \\
\hline$[45 /-45 /-45 / 45]$ & 11.2528 & 7.08 & 16.8792 & 1.417 & 2.81 & 68.017 \\
\hline$[60 /-60 /-60 / 60]$ & 6.15 & 11.83 & 9.2311 & 2.3663 & 1.54 & 113.58 \\
\hline$[75 /-75 /-75 / 75]$ & 4.59 & 14.78 & 6.8941 & 2.9577 & 1.149 & 141.96 \\
\hline$[90 /-90 /-90 / 90]$ & 4.26 & 15.62 & 6.4 & 3.125 & 1.06 & 150 \\
\hline$[0 / 90 / 90 / 0]$ & 126.7 & 1.0051 & 190.0751 & 0.201 & 31.67 & 9.6494 \\
\hline
\end{tabular}




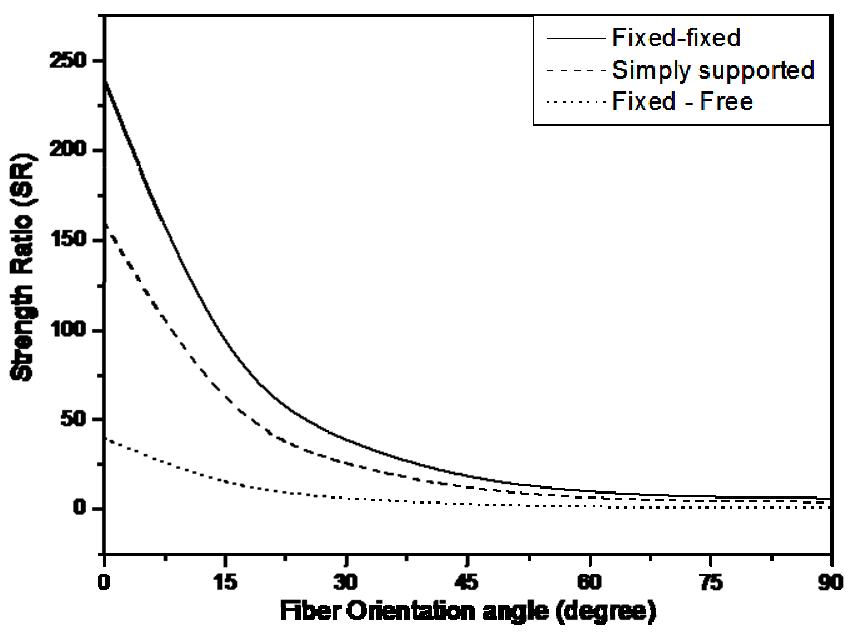

Fig.3. Effect of the fiber orientation angle on the strength ratio for different boundary conditions.

\subsection{Effect of thermal load on the strength ratio of a composite beam}

During fabrication, a composite laminate is subjected to a variety of thermal environments which introduce residual stresses. These stresses are called thermal stresses. They affect the performance of the composite laminate. If the laminate is exposed to only one thermal environment, i.e. if it is cooled from curing temperature to room temperature or heated from room temperature to processing temperature, then the stress generated in it is called residual thermal stress. Now when the same laminate is subjected to mechanical load, then the stress developed is called thermo mechanical stress. A comparison of the strength ratio calculated by Tsai- $\mathrm{Wu}$ failure criteria for a graphite epoxy laminated composite beam subjected to mechanical and thermo mechanical loading is presented. The strength ratio is calculated for the angle from $0^{\circ}$ to $90^{\circ}$ at an increment of $15^{\circ}$. It is assumed that any change in value within $15^{\circ}$ is neglected. Figure 4 shows the strength ratio for a range of orientation angles of angle ply laminate and cross ply laminate subjected to mechanical and thermo mechanical loading. It is found that due to negative thermal stress, the thermo mechanical stress increases and the strength ratio of the beam under thermo mechanical load is less than that of mechanical load (Tab.4).

Table 4. Comparison of the strength ratio of a composite beam subjected to mechanical (UDL=1000 $\mathrm{N} / \mathrm{m}$ ) and thermo mechanical load $\left(\Delta T=-75^{\circ} \mathrm{C}, U D L=1000 \mathrm{~N} / \mathrm{m}\right)$.

\begin{tabular}{|c|c|c|c|c|c|c|}
\hline & \multicolumn{5}{|c|}{ Strength ratio based on first ply failure load } \\
\hline & \multicolumn{2}{|c|}{ Simply Supported } & \multicolumn{2}{c|}{ Fixed-Fixed } & \multicolumn{2}{c|}{ Fixed-Free } \\
\hline $\begin{array}{c}\text { Fiber Orientation } \\
\text { angle }\end{array}$ & Mechanical & $\begin{array}{c}\text { Thermo } \\
\text { mechanical }\end{array}$ & Mechanical & $\begin{array}{c}\text { Thermo } \\
\text { mechanical }\end{array}$ & Mechanical & $\begin{array}{c}\text { Thermo } \\
\text { mechanical }\end{array}$ \\
\hline$[0 /-0 /-0 / 0]$ & 160 & 160 & 240 & 240 & 40 & 40 \\
\hline$[15 /-15 /-15 / 15]$ & 47.85 & 42.5718 & 71.7765 & 63.857 & 11.96 & 10.64 \\
\hline$[30 /-30 /-30 / 30]$ & 24.2577 & 20.147 & 36.3866 & 30.22 & 6.06 & 5.036 \\
\hline$[45 /-45 /-45 / 45]$ & 11.2528 & 8.16 & 16.8792 & 12.247 & 2.81 & 2.04 \\
\hline$[60 /-60 /-60 / 60]$ & 6.15 & 4.94 & 9.2311 & 7.411 & 1.54 & 1.235 \\
\hline$[75 /-75 /-75 / 75]$ & 4.59 & 4.32 & 6.8941 & 6.4837 & 1.149 & 1.08 \\
\hline$[90 /-90 /-90 / 90]$ & 4.26 & 4.2667 & 6.4 & 6.4 & 1.06 & 1.06 \\
\hline$[0 / 90 / 90 / 0]$ & 126.7 & 79.8749 & 190.0751 & 119.8124 & 31.67 & 19.96 \\
\hline
\end{tabular}




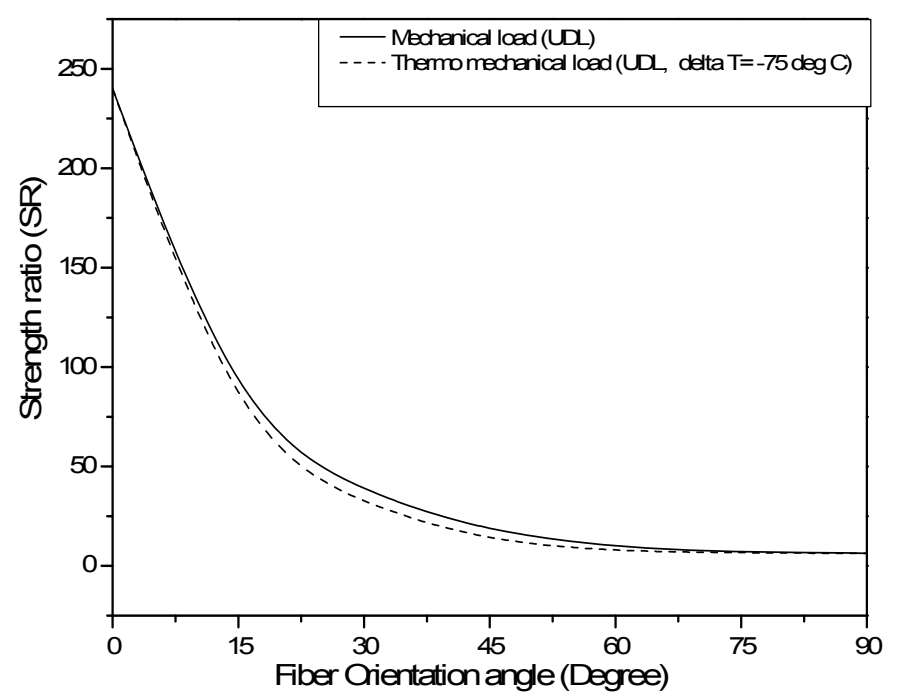

Fig.4. Comparison of the strength ratio obtained for mechanical and thermo mechanical load for different fiber orientation angle for a composite fixed beam.

\subsection{Effect of aspect ratio $(\mathrm{a} / \mathrm{h})$ on the strength ratio based on FPF load}

Aspect ratio is the ratio of length to total thickness of a laminated composite beam. As the aspect ratio increases, thickness of the beam decreases keeping length of the beam constant and the strength ratio decreases and becomes constant (Fig.5). The strength ratio is more significant for the beam whose aspect ratio is less than 10 because for the aspect ratio 5 to 10 , the strength ratio decreases sharply and after 10 , it decreases gradually and becomes almost constant after 40 . So, the strength ratio does not depend upon the aspect ratio when the composite laminated beam has the ratio 40 and above.

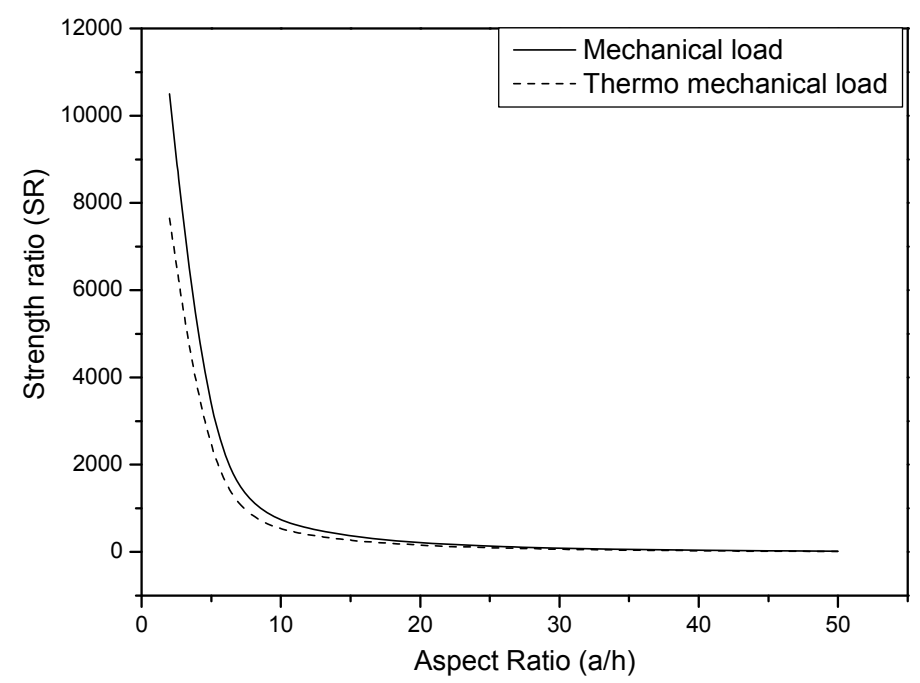

Fig.5. Effect of the aspect ratio on the strength ratio for a fixed composite beam for mechanical and thermo mechanical load. 


\subsection{Mode of failure}

The mode of failure is determined by using the non interactive failure theory (maximum stress theory). A laminated composite laminate may fail due to breakage of fiber, matrix cracking and shear failure. The mode of failure of laminate is very important to find out the ultimate failure load and to predict the nature of failure of lamina within the laminate so that proper preventive measures may be taken to avoid failure. Table 5 shows the mode of failure of a composite beam under mechanical and thermo mechanical load.

Table 5. Mode of failure of a composite beam for different boundary conditions subjected to mechanical and thermo mechanical.

\begin{tabular}{|c|c|c|c|c|c|c|}
\hline B.C & & \multicolumn{3}{|c|}{ Mechanical Load } & \multicolumn{2}{|c|}{ Thermo mechanical load } \\
\hline \multirow{9}{*}{ 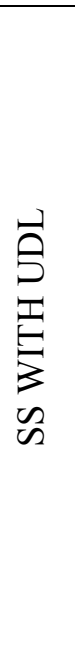 } & $\begin{array}{l}\text { Fiber } \\
\text { Orientation } \\
\text { angle }\end{array}$ & $\begin{array}{c}\text { Failure } \\
\text { location }\end{array}$ & $\begin{array}{l}\text { First } \\
\text { failed } \\
\text { ply }\end{array}$ & Mode of failure & $\begin{array}{l}\text { First } \\
\text { failed } \\
\text { ply }\end{array}$ & Mode of failure \\
\hline & {$[0 /-0 /-0 / 0]$} & $(0.5,0.5)$ & 1,4 & $\begin{array}{l}\text { 4- Fiber failure in tension, } 1- \\
\text { Fiber failure in Compression }\end{array}$ & 1,4 & $\begin{array}{l}\text { 1- Fiber failure in } \\
\text { compression, 4-Fiber } \\
\text { failure in tension }\end{array}$ \\
\hline & {$[15 /-15 /-15 / 15]$} & $(0.5,0.5)$ & 4 & Fiber failure in tension & 4 & Shear failure in comp \\
\hline & {$[30 /-30 /-30 / 30]$} & $(0.5,0.5)$ & 1 & Fiber failure in compression & 4 & Matrix failure in tension \\
\hline & {$[45 /-45 /-45 / 45]$} & $(0.5,0.5)$ & 4 & Fiber failure in tension & 4 & Matrix failure in tension \\
\hline & {$[60 /-60 /-60 / 60]$} & $(0.5,0.5)$ & 4 & Matrix failure in tension & 4 & Matrix failure in tension \\
\hline & {$[75 /-75 /-75 / 75]$} & $(0.5,0.5)$ & 4 & Matrix failure in tension & 4 & Matrix failure in tension \\
\hline & {$[90 /-90 /-90 / 90]$} & $(0.5,0.5)$ & 4 & Matrix failure in tension & 4 & Matrix failure in tension \\
\hline & {$[0 / 90 / 90 / 0]$} & $(0.5,0.5)$ & 4 & Fiber failure in tension & 3 & Fiber failure in compression \\
\hline \multirow{8}{*}{ 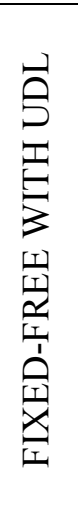 } & {$[0 /-0 /-0 / 0]$} & $(0,0)$ & 1,4 & $\begin{array}{l}\text { 4- Fiber failure in } \\
\text { compression, 1-Fiber failure in } \\
\text { tension }\end{array}$ & 1,4 & $\begin{array}{l}\text { 4- Fiber failure in } \\
\text { compression, 1-Fiber } \\
\text { failure in tension }\end{array}$ \\
\hline & {$[15 /-15 /-15 / 15]$} & $(0,0)$ & 1 & Fiber failure in tension & 1 & Fiber failure in tension \\
\hline & {$[30 /-30 /-30 / 30]$} & $(0,0)$ & 4 & Fiber failure in compression & 1 & Fiber failure in tension \\
\hline & {$[45 /-45 /-45 / 45]$} & $(0,0)$ & 1 & Fiber failure in tension & 1 & Matrix failure in tension \\
\hline & {$[60 /-60 /-60 / 60]$} & $(0,0)$ & 1 & Matrix failure in tension & 1 & Matrix failure in tension \\
\hline & {$[75 /-75 /-75 / 75]$} & $(0,0)$ & 1 & Matrix failure in tension & 1 & Matrix failure in tension \\
\hline & {$[90 /-90 /-90 / 90]$} & $(0,0)$ & 1 & Matrix failure in tension & 1 & Matrix failure in tension \\
\hline & {$[0 / 90 / 90 / 0]$} & $(0,0)$ & 1 & Fiber failure in tension & 2 & Fiber failure in compression \\
\hline \multirow{8}{*}{ 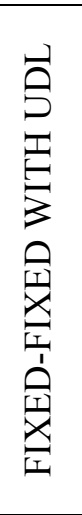 } & {$[0 /-0 /-0 / 0]$} & $(0,0)$ & 1,4 & $\begin{array}{l}\text { 4- Fiber failure in compression, } \\
\text { 1-Fiber failure in tension }\end{array}$ & 1,4 & $\begin{array}{l}\text { 4- Fiber failure in } \\
\text { compression, 1-Fiber } \\
\text { failure in tension }\end{array}$ \\
\hline & {$[15 /-15 /-15 / 15]$} & $(0,0)$ & 1 & Fiber failure in tension & 1 & Shear failure \\
\hline & {$[30 /-30 /-30 / 30]$} & $(0,0)$ & 4 & Fiber failure in compression & 1 & Matrix failure in tension \\
\hline & {$[45 /-45 /-45 / 45]$} & $(0,0)$ & 1 & Shear failure & 1 & Matrix failure in tension \\
\hline & {$[60 /-60 /-60 / 60]$} & $(0,0)$ & 1 & Matrix failure in tension & 1 & Matrix failure in tension \\
\hline & {$[75 /-75 /-75 / 75]$} & $(0,0)$ & 1 & Matrix failure in tension & 1 & Matrix failure in tension \\
\hline & {$[90 /-90 /-90 / 90]$} & $(0,0)$ & 1 & Matrix failure in tension & 1 & Matrix failure in tension \\
\hline & {$[0 / 90 / 90 / 0]$} & $(0,0)$ & 1 & Fiber failure in tension & 2 & Matrix failure in tension \\
\hline
\end{tabular}




\subsection{Analysis of hybrid composite beam}

A comparative study of the deflection, strength ratio, cost and mass of a graphite epoxy and glass epoxy composite beam for different boundary conditions is presented in Tab.6 which shows that deflection of the glass epoxy composite is greater than that of the graphite epoxy. Also, the cost per ply of graphite epoxy is 2.5 times more than that of the glass epoxy and the density of glass epoxy is less than that of graphite epoxy. Laminated composite design includes optimization in cost, mass, strength ratio; stiffness, etc. Hybrid composite is the optimum combination of different composite materials since it minimizes cost and mass without compromising its strength. Plies of graphite and glass epoxy are combined in such a way that it minimizes cost and mass.

It is found that G-C-C-G (G: graphite epoxy and C: Glass epoxy material) combination of composite materials (hybrid composite) shows the minimum transverse deflection as compared to Glass/Epoxy composite and very close to Graphite/Epoxy composite (Tab.7). Graphite/Epoxy composite forms the facing material and glass epoxy composite forms the inner core layer. The longitudinal tensile and compressive strengths are larger in the graphite/epoxy lamina than in a glass/epoxy lamina. Also hybrid composite shows minimum mass as compared to Glass/Epoxy and the mass is slightly greater than Graphite/Epoxy and also its cost is less than Graphite/Epoxy but greater than Glass/Epoxy composite. Based on first ply failure analysis, the strength ratio (SR) of G-C-C-G hybrid composite is superior than glass/epoxy composite and close to the strength ratio of Graphite/Epoxy. Therefore, G-C-C-G, hybrid composite is relatively superior to that of constituent composite material.

Table 6. Comparative study of a composite beam composed of four plies of different composite materials for different boundary conditions.

\begin{tabular}{|c|c|c|c|c|c|c|}
\hline \multirow[t]{2}{*}{ B.C } & \multirow[t]{2}{*}{ Thickness/Ply $(m)$} & \multirow[t]{2}{*}{$\begin{array}{c}\text { Fiber orientation } \\
\text { Angle }\end{array}$} & \multicolumn{4}{|c|}{ Graphite/Epoxy (G) } \\
\hline & & & SR & wbar & Cost & Mass (kg) \\
\hline \multirow{2}{*}{ Fixed-Fixed } & \multirow{2}{*}{0.005} & {$\left[\begin{array}{llll}45 & -45 & -45 & 45\end{array}\right]$} & 16.88 & 1.42 & 1944 & 6.48 \\
\hline & & {$\left[\begin{array}{llll}0 & 90 & 90 & 0\end{array}\right]$} & 190.07 & 0.201 & 1944 & 6.48 \\
\hline \multirow{2}{*}{ SS with UDL } & \multirow{2}{*}{0.005} & {$\left[\begin{array}{llll}45 & -45 & -45 & 45\end{array}\right]$} & 11.25 & 7.08 & 1944 & 6.48 \\
\hline & & {$\left[\begin{array}{llll}0 & 90 & 90 & 0\end{array}\right]$} & 126.71 & 1 & 1944 & 6.48 \\
\hline \multirow{3}{*}{ Fixed-Free with UDL } & \multirow{2}{*}{0.005} & {$\left[\begin{array}{llll}45 & -45 & -45 & 45\end{array}\right]$} & 2.81 & 68.02 & 1944 & 6.48 \\
\hline & & {$\left[\begin{array}{llll}0 & 90 & 90 & 0\end{array}\right]$} & 31.68 & 9.65 & 1944 & 6.48 \\
\hline & & & \multicolumn{4}{|c|}{ Glass/Epoxy (C) } \\
\hline \multirow{2}{*}{ Fixed-Fixed } & \multirow{2}{*}{0.005} & {$\left[\begin{array}{llll}45 & -45 & -45 & 45\end{array}\right]$} & 11.68 & 2.21 & 714 & 7.14 \\
\hline & & {$\left[\begin{array}{llll}0 & 90 & 90 & 0\end{array}\right]$} & 144.84 & 0.74 & 714 & 7.14 \\
\hline \multirow{2}{*}{ SS with UDL } & \multirow{2}{*}{0.005} & {$\left[\begin{array}{llll}45 & -45 & -45 & 45\end{array}\right]$} & 7.79 & 11.06 & 714 & 7.14 \\
\hline & & {$\left[\begin{array}{llll}0 & 90 & 90 & 0\end{array}\right]$} & 28.3 & 3.70 & 714 & 7.14 \\
\hline \multirow{3}{*}{ Fixed-Free with UDL } & \multirow{2}{*}{0.005} & {$\left[\begin{array}{llll}45 & -45 & -45 & 45\end{array}\right]$} & 1.95 & 106.24 & 714 & 7.14 \\
\hline & & {$\left[\begin{array}{llll}0 & 90 & 90 & 0\end{array}\right]$} & 7.07 & 35.51 & 714 & 7.14 \\
\hline & & & \multicolumn{4}{|c|}{ Hybrid [G-C-C-G] } \\
\hline \multirow{2}{*}{ Fixed-Fixed } & \multirow{2}{*}{0.005} & {$\left[\begin{array}{llll}45 & -45 & -45 & 45\end{array}\right]$} & 15.8 & 1.44 & 1329 & 6.81 \\
\hline & & {$\left[\begin{array}{llll}0 & 90 & 90 & 0\end{array}\right]$} & 203 & 0.16 & 1329 & 6.81 \\
\hline \multirow{2}{*}{ SS with UDL } & \multirow{2}{*}{0.005} & {$\left[\begin{array}{llll}45 & -45 & -45 & 45\end{array}\right]$} & 8.02 & 7.20 & 1329 & 6.81 \\
\hline & & {$\left[\begin{array}{llll}0 & 90 & 90 & 0\end{array}\right]$} & 96.29 & 0.81 & 1329 & 6.81 \\
\hline \multirow{2}{*}{ Fixed-Free with UDL } & \multirow{2}{*}{0.005} & {$\left[\begin{array}{llll}45 & -45 & -45 & 45\end{array}\right]$} & 2 & 69.14 & 1329 & 6.81 \\
\hline & & {$\left[\begin{array}{llll}0 & 90 & 90 & 0\end{array}\right]$} & 24.07 & 7.77 & 1329 & 6.81 \\
\hline
\end{tabular}


Table 7. Properties of composite materials.

\begin{tabular}{|l|c|c|c|}
\hline \multicolumn{1}{|c|}{ Property } & Unit & Graphite/Epoxy & Glass/Epoxy \\
\hline Longitudinal elastic modulus & $\mathrm{GPa}$ & 181 & 38.6 \\
\hline Transverse elastic modulus & $\mathrm{GPa}$ & 10.3 & 8.27 \\
\hline Major Poisson's ratio & & 0.28 & 0.26 \\
\hline Shear modulus & $\mathrm{GPa}$ & 7.17 & 4.14 \\
\hline Ultimate longitudinal tensile strength & $\mathrm{MPa}$ & 1500 & 1062 \\
\hline Ultimate longitudinal compressive strength & $\mathrm{MPa}$ & 1500 & 610 \\
\hline Ultimate transverse tensile strength & $\mathrm{MPa}$ & 40 & 31 \\
\hline Ultimate transverse compressive strength & $\mathrm{MPa}$ & 246 & 118 \\
\hline Ultimate in-plane shear strength & $\mathrm{MPa}$ & 68 & 72 \\
\hline Density & $\mathrm{g} / \mathrm{cm}^{3}$ & 1.59 & 1.97 \\
\hline
\end{tabular}

\section{Conclusion}

The strength ratio is calculated and compared using different failure theories, based on first ply failure load, for different fiber orientation angles for a laminated composite beam subjected to mechanical load (UDL) and thermo mechanical load (UDL and $\Delta T$ ). The strength ratio is maximum at $0^{\circ}$ orientation angle and it gradually decreases to $90^{\circ}$. Moreover, the strength ratio of the beam under mechanical load is greater than that of the beam under thermo mechanical load. The strength ratio calculated from non interactive failure theory is greater than that from interactive failure theory. As the aspect ratio increases, the thickness of the beam decreases keeping length of beam constant, and strength ratio decreases and becomes constant. The mode of failure is determined by non interactive failure theory because interactive failure theory cannot determine the mode of failure. The hybrid composite beam is relatively economical, lighter and superior to the beam made up of its constituent materials.

\section{Nomenclature}

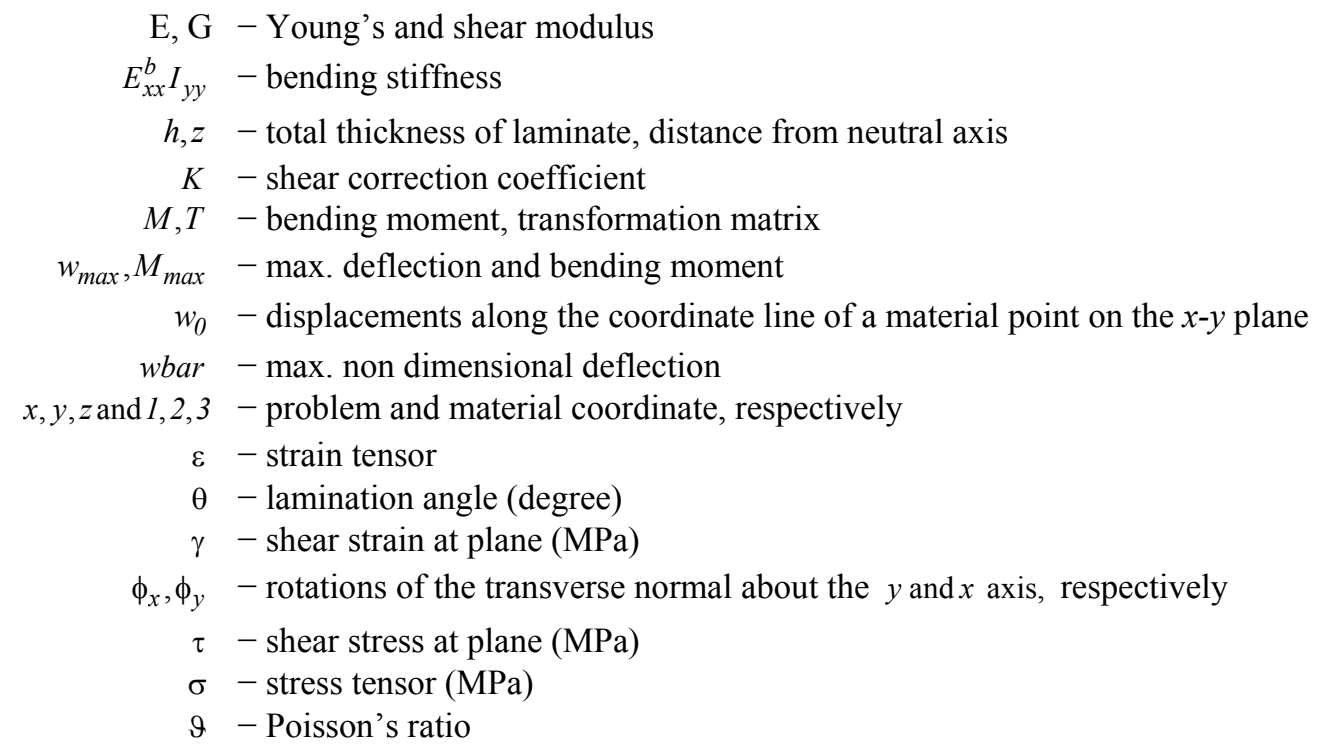




\section{References}

[1] Borkar R.R., Sayyad A.S. and Ghumare S.M. (2013): Assessment of refined beam theories for the bending analysis of composite beam. - International Journal of Advanced Technology In Civil Engineering, pp.2231-5721, vol.2, No.1, pp.73-78.

[2] Trung-Kien Nguyen, Ngoc-Duong Nguyen, Thuc P. Vo b,d and Huu-Tai Thai (2017): Trigonometric-series solution for analysis of laminated composite beams. - Composite Structures, vol.160, pp.142-151.

[3] Atteshamuddin S. Sayyad and Yuwaraj M. Ghugal (2017): Bending, buckling and free vibration of laminated composite and sandwich beams: A critical review of literature. - Composite Structures, vol.171, pp.486-504.

[4] Meng M., Le H.R., Rizvi M.J. and Grove S.M. (2015): 3D FEA modelling of laminated composites in bending and their failure mechanisms. - Composite Structures, vol.119, pp.693-708.

[5] Autar K. Kaw (2006): Mechanics of composite materials. Second edition. - Taylor and Francis.

[6] Reddy J.N. (1997): Mechanics of laminated composite plate and shells- theory and analysis. - Second edition, CRC Press.

[7] Timoshenko and Krieger (1959): Theory of plates and shells. Second edition. - Mc-Graw Hill.

Received: August 22, 2019

Revised: November 19, 2019 